\title{
The Anomalous Origin of the Left Coronary Artery from the Pulmonary Artery (ALCAPA) in Senegal
}

\author{
Mohamed Leye ${ }^{1,3}$, Fatou Aw ${ }^{2}$, Adama Sawadogo 3, *, Maria Helena Diame ${ }^{1}$, Momar Dioum², \\ Désiré Alain Affangla ${ }^{1}$, Simon Manga ${ }^{4}$, Abdoulaye Ndoye Diop ${ }^{5}$, Bassirou Bah ${ }^{1}$, \\ Magalie Kaya Samba ${ }^{2}$, Alassane Aliou Ngaide ${ }^{2}$, Alassane Mbaye ${ }^{2}$, Modibo Doumbia ${ }^{3}$, \\ Djibril Marie Ba ${ }^{1}$, Rosette Godonou ${ }^{1}$, Abdoul Kane ${ }^{2}$ \\ ${ }^{1}$ Unit of Training and Research in Medical Sciences, University of Thies, Thies, Senegal \\ ${ }^{2}$ Department of Cardiology, Cheikh Anta Diop University, Dakar, Senegal \\ ${ }^{3}$ Department of Cardiovascular and Thoracic Surgery, Cheikh Anta Diop University, Dakar, Senegal \\ ${ }^{4}$ Department of Cardiology, University of Ziguinchor, Ziguinchor, Senagal \\ ${ }^{5}$ Department of Radiology, University of Saint Louis, Saint Louis, Senegal
}

\section{Email address:}

leyemohamed@gmail.com (M. Leye), fatoukine@yahoo.fr (F. Aw), adamsaw2000@yahoo.fr (A. Sawadogo), hdiame@hotmail.com (M. H. Diame), momar.dioum@yahoo.fr (M. Dioum), docalaf@gmail.com (D. A. Affangla), mangasimon2@gmail.com (S. Manga),ndoyediop@yahoo.com (A. N. Diop), bachirov6@gmail.com (B. Bah), magaliekayasamba@gmail.com (M. K. Samba),ngaideaa@hotmail.fr (A. A. Ngaide), ambaye8@hotmail.com (A. Mbaye), modibodoumbia25@yahoo.fr (M. Doumbia), gabi.11ba@yahoo.fr (D. M. Ba), rosettegodonou@gmail.com (R. Godonou), abdoulkane.cardio@gmail.com (A. Kane)

${ }^{*}$ Corresponding author

\section{To cite this article:}

Mohamed Leye, Fatou Aw, Adama Sawadogo, Maria Helena Diame, Momar Dioum, Désiré Alain Affangla, Simon Manga, Abdoulaye Ndoye Diop, Bassirou Bah, Magalie Kaya Samba, Alassane Aliou Ngaide, Alassane Mbaye, Modibo Doumbia, Djibril Marie Ba, Rosette Godonou, Abdoul Kane. The Anomalous Origin of the Left Coronary Artery from the Pulmonary Artery (ALCAPA) in Senegal. International Journal of Cardiovascular and Thoracic Surgery. Vol. 3, No. 2, 2017, pp. 9-13. doi: 10.11648/j.ijcts.20170302.12

Received: May 21, 2017; Accepted: June 19, 2017; Published: July 25, 2017

\begin{abstract}
The anomalous origin of the left coronary artery from the pulmonary artery (ALCAPA) is a rare malformation that represents less than $0.5 \%$ of the congenital heart diseases. The common clinical feature is congestive heart failure. The treatment is strictly a surgical repair. The authors report the first 3 cases of ALCAPA diagnosed in Senegal in infants under the age of 1 year old. Two were successfully treated by surgical repair; the $3^{\text {rd }}$ child is still waiting for surgical repair to be performed abroad.
\end{abstract}

Keywords: ALCAPA, Africa, Dilated Cardiomyopathy, Coronary Artery Re-implantation, Infant, Ischemic Heart

\section{Introduction}

The anomalous left coronary artery originating from the pulmonary artery (ALCAPA) or Bland-White-Garland syndrome is an extremely rare congenital malformation that represents less than $0.5 \%$ of the congenital heart diseases [11]. The prognosis could be bad as this malformation leads to left ventricle (LV) failure. Only a few numbers of untreated cases will survive after infancy. Emergent surgical therapy is sometimes indicated [12]. In this work we emphasize the role of ECG and echocardiogram in the early diagnosis of ALCAPA in the underprivileged countries. In turn, this early diagnosis allows surgical repair to be performed on time.

\section{Clinical Cases}

\subsection{Case 1}

SM was a baby aged 3 months old of male sex. The pregnancy had good course and the birth weight was $3500 \mathrm{~g}$. There was no parental consanguinity. He was admitted in our unit for dyspnea and cardiomegaly on chest $\mathrm{X}$ rays. The 
physical examination found a good physical appearance; the weight was $10 \mathrm{~kg}$ and the oxygen saturation was $99 \%$. The heart rate was 100 per min. Auscultation revealed murmur (intensity of 3/6) at the apex. ECG showed deep Q wave at V5, V6 and D1AVL. There were ST elevation at V5 V6, negative $\mathrm{T}$ wave, LVH and left axis (QRS $-20^{\circ}$ ) (Figure 1). Echocardiogram (figure 2, 3) showed dilated LV with 43 and $31 \mathrm{~mm}$ respectively at end diastole and systole $(Z=+6$ with parameter $Z$ score). The LV systolic function was decreased and there was a global hypokinesia more on infero-lateral zone; the LVEF was $35 \%$. The LCA was originating from the main PA and there was ischemic-like mitral regurgitation. The CT scan has confirmed ALCAPA (figure 4). The biology showed anemia. A medical management was started; it consisted of furosemide, captoril and iron. Then a surgical repair was indicated; the patient was transferred to the University Hospitals of Geneva, Switzerland. He benefited from surgical management that consisted of transposition of the LCA from the main PA, separation of the left anterior descending to the circumflex and then re-implantation of them separately into the ascending aorta. The repair was performed under CPB. The early postoperative courses were complicated by pneumonia due to $\mathrm{M}$. catarrhalis and $\mathrm{H}$. influenza leading to left pleural effusion. This was treated by thoracocentesis and antibiotic (amoxicillin clavulanate). The hospital stay lasted 21 days then he discharged with a medical treatment that consisted of iron, aspirin, enalapril, furosemide and spironolactone. The check-up 4 years after the operation showed a normal ECG (figure 5) with normal LV function.

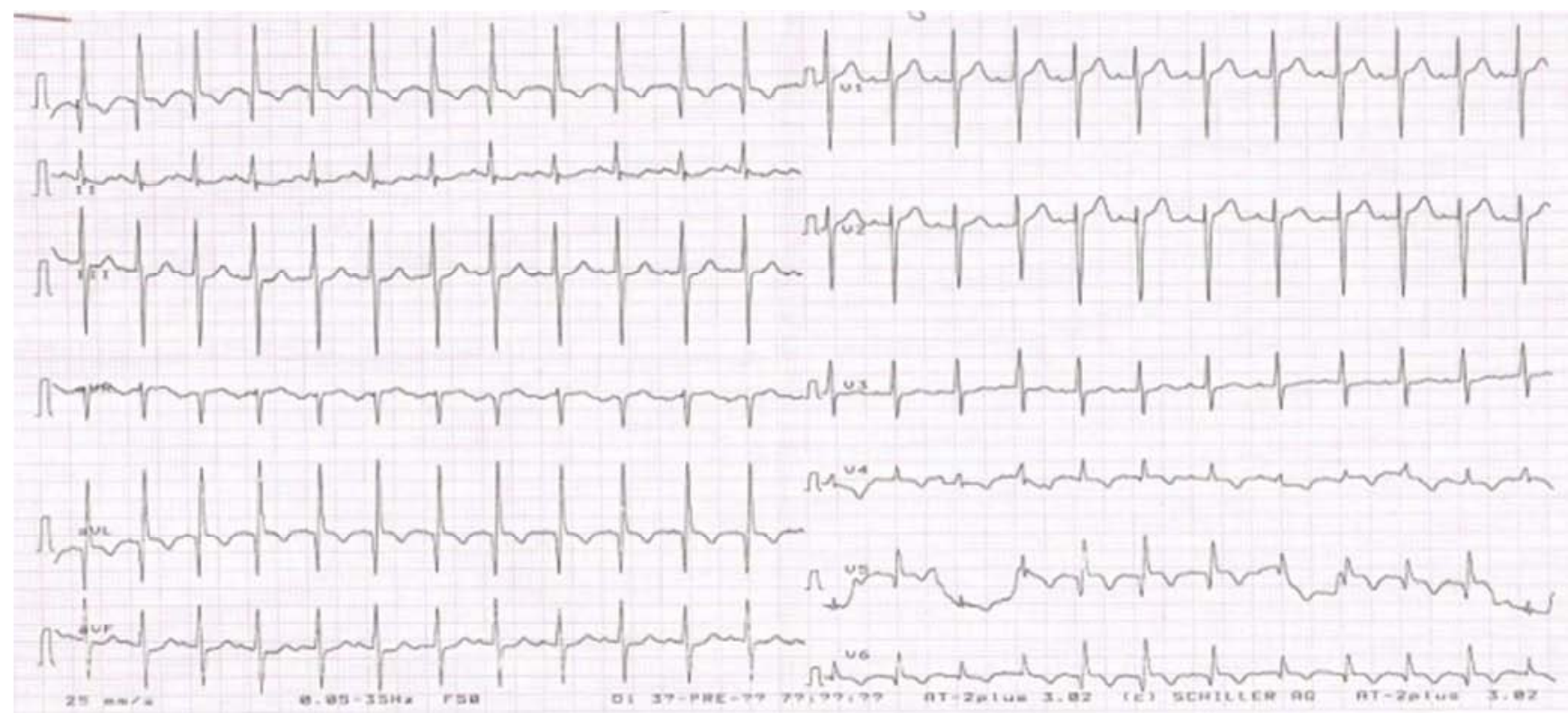

Figure 1. EKG showing deep $Q$ wave at V5, V6 and D1AVL.

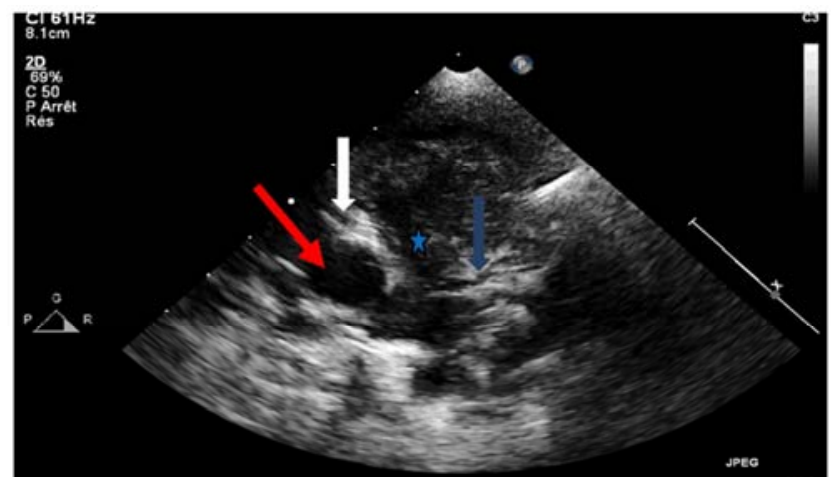

Figure 2. 2D TTE parasternal short axis view showing the LCA (blue arrow).

There were ST elevation at V5 V6 and negative T wave coming from the main PA (blue star), and RCA (white arrow) coming from the aorta (red arrow).

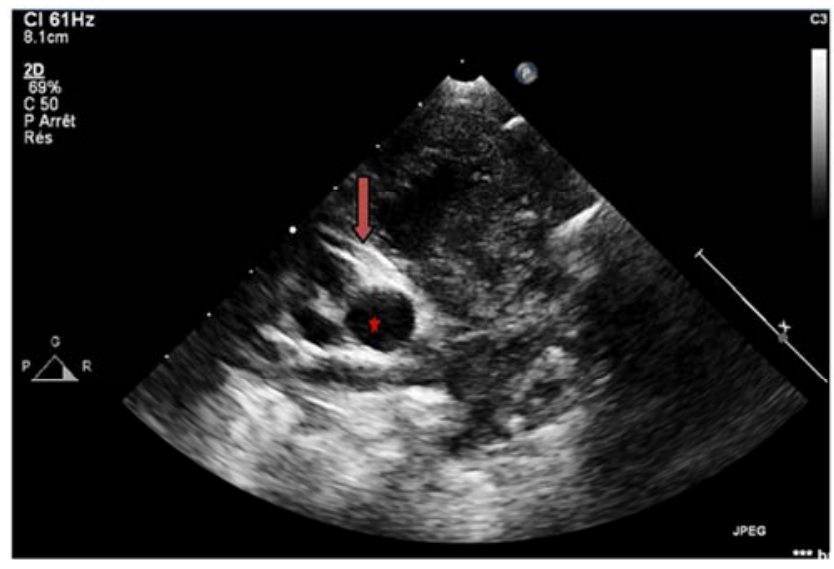

Figure 3. TTE parasternal short axis view $2 D$ mode showing a dilated $R C A$ (red arrow) coming from right anterior Valsalva sinus of the aorta (red star). 


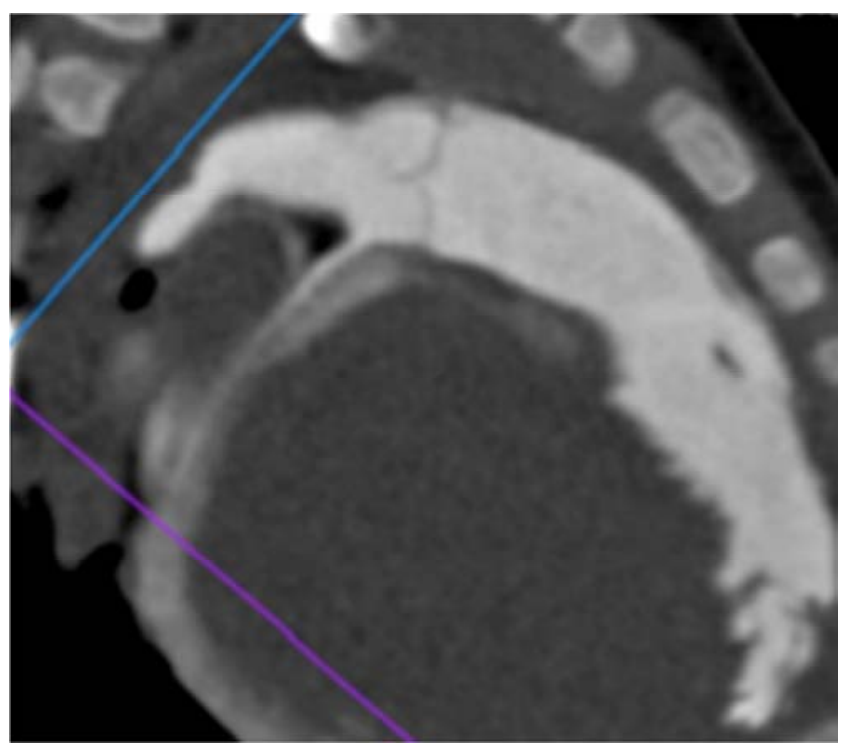

Figure 4. Cardiac CT, MPR reconstruction showing the circumflex artery from the main pulmonary artery.

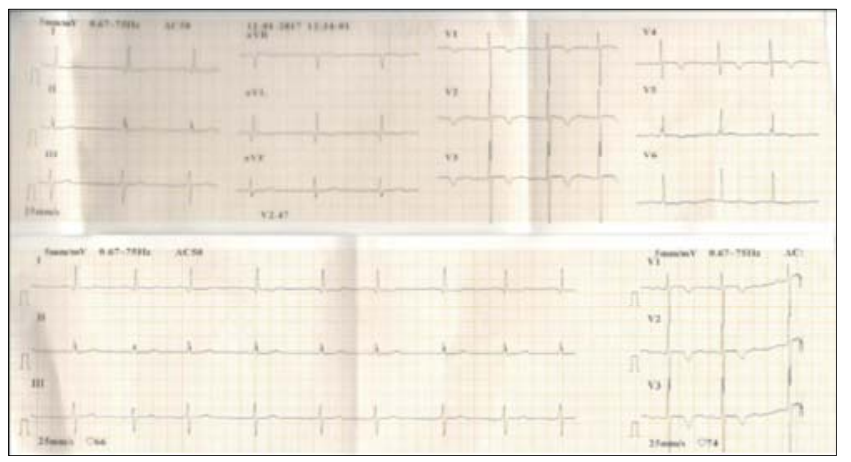

Figure 5. ECG of SM 4 years after surgical correction of the ALCAPA.

\subsection{Case 2}

NAT, a female sex baby was aged 6 months. Her birth weight was $2600 \mathrm{~g}$. There was no consanguinity between the parents. One month after the birth, she presented dyspnea, hyper sweating during breastfeeding and unusual crying. Then she was hospitalized in pediatrics for bronchiolitis and anemia. The chest $\mathrm{x}$ rays showed cardiomegaly, doubleedged left atrium and convex left border. ECG showed LV hypertrophy, deep Q wave at D1, aVL, V5 and V6 in addition to repolarization abnormality. Echocardiogram (figure 6) showed anomalous origin of the LCA originating from the PA stem; there was a severe hypokinetic dilated cardiomyopathy (DMC); the LV end of diastole diameter and end of systole diameter were respectively 48 and $42 \mathrm{~mm}$; LVEF was $27 \%$; shortening fraction was $8.97 \%$ and LAd $24.5 \mathrm{~mm}$ (Z-score + 4.84). There was a moderate mitral regurgitation due to dilated annulus and dilated RCA. At the admission, the cardiovascular examination found muffled heart sounds. There were no murmurs or other abnormal sign. The physical condition had progressively improved by medical treatment that included furosemide $0.5 \mathrm{mg} / \mathrm{kg}$, spironolactone $1 \mathrm{mg} / \mathrm{kg}$ bd, captopril $9.375 \mathrm{mg}$, digoxin $5 \mathrm{mcg} / \mathrm{kg}$ bd and aspirin 5 $\mathrm{mg} / \mathrm{kg}$. NAT was operated 11 months later in Paris, France. It consisted of median sternotomy for re-implantation of the LCA on the aortic root and closure of the PA hole by pericardial patch. CPB was used to perform the operation. Immediate postoperative course was complicated by bronchitis due to haemophilus that was successfully managed by amoxicillin + clavulanic acid. The control echography showed a remaining failure of LV function with high filling pressure. The output was preserved. The later course was improved due to furosemide and vasodilators. When she went back to our department, she was free of dyspnea and had got 2 more kilograms of weight. After a follow up of 3 years, she presented a good clinical state and normal echocardiogram (figure 7).

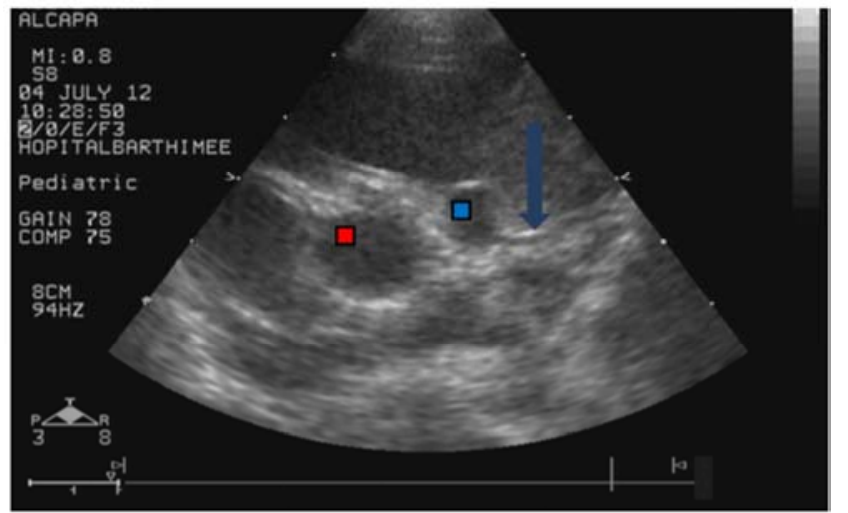

Figure 6. TTE parasternal short axis view $2 D$ mode showing the LCA (blue arrow) originating from the main PA (blue square) and not from Aorta (red square).

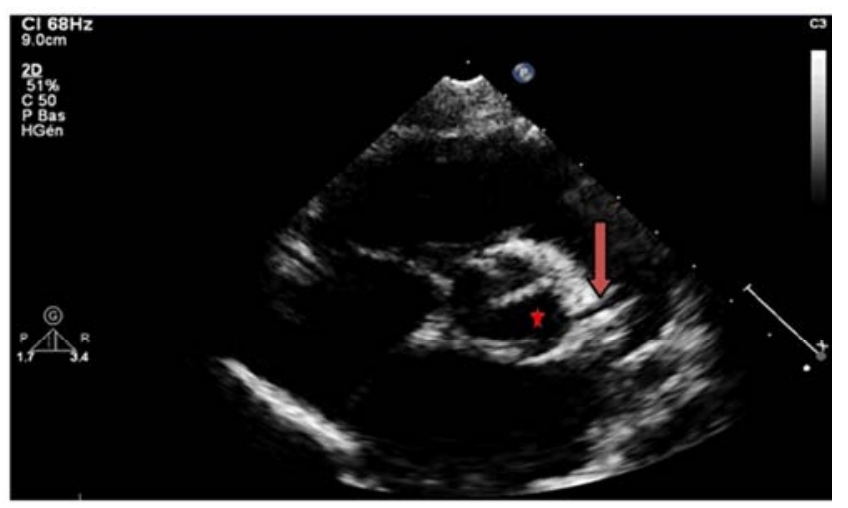

Figure 7. TTE parasternal short axis view 2D Mode S/p surgical Reparation showing a left coronary artery (red arrow) coming from the left anterior Valsalva sinus of the aorta (red star).

\subsection{Case 3}

AB was 10 month-old female baby. She was suffering from cough, fever and insomnia since she was 4 month-old. She was hospitalized 3 times for bronchiolitis but there was not complete recovery from the symptoms. In her previous medical history, a first-degree consanguinity was noticed between the parents; the birth weight was $1500 \mathrm{~g}$; she was probably preterm baby. The physical examination found a failure to thrive and crackling rales. Chest $\mathrm{X}$ rays (figure 8) showed massive cardiomegaly. The ECG showed LV hypo perfusion signs with deep Q wave in Leads D1 AVL and V5 
(figure 9). The echocardiogram (figure 10) showed LCA originating from the PA but the collateral branches were not seen. The flux presented steal syndrome from the LCA to PA and the LV was dilated. There was LV failure as the LVEF was $15-20 \%$ and the shortening fraction was $8.75 \%$; the IVSd was 5.8 (Z-score +2.86). In addition there was a global hypokinesia which was severe on the anterior and septal zones. Laboratory tests were normal. We indicated a surgical repair. Since then the parents are been doing their best to transfer her abroad as the local medical conditions do not allow safe surgical management. Meanwhile we have prescribed medical therapy that consists of furosemide, captopril and digoxin.

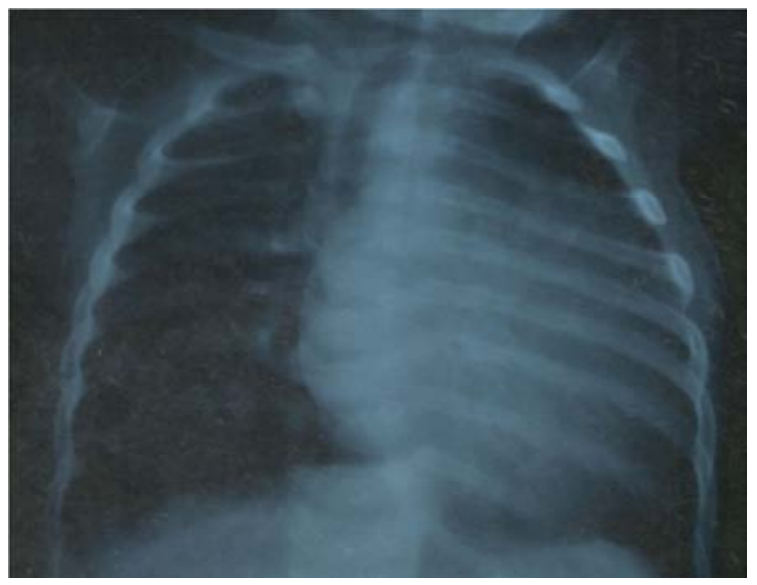

Figure 8. Chest X-rays showing.
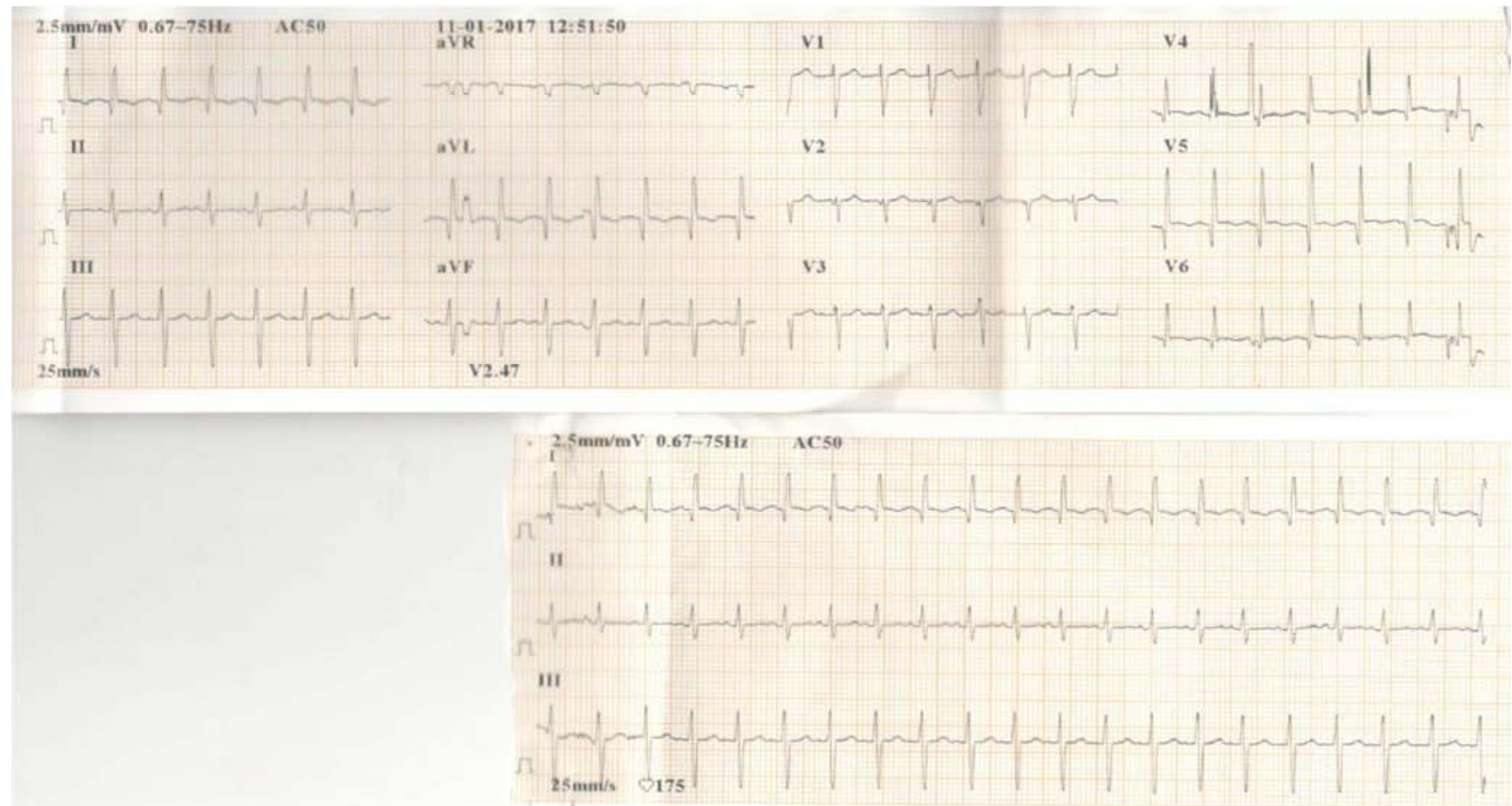

Figure 9. ECG of patient 3 with signs of ALCAPA massive cardiomegaly.

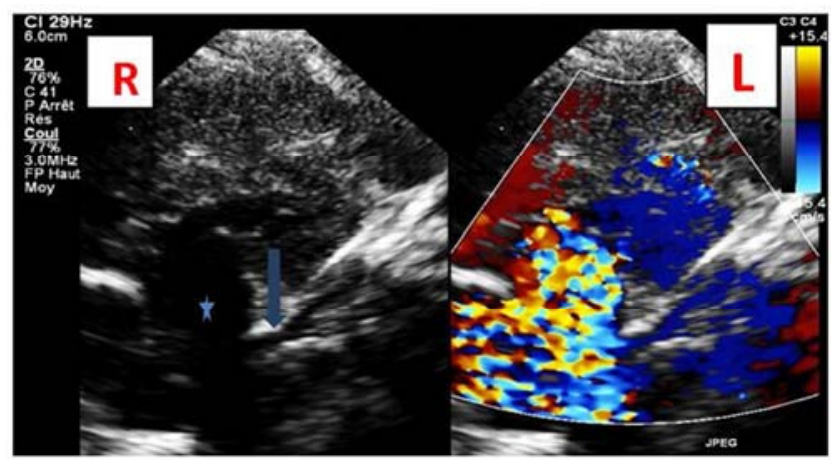

Figure 10. TTE parasternal short axis view color compare mode-2D $(R)$ and color mode (L) showing the LCA (blue arrow) coming from the main PA (blue star) with two branches : Left anterior descending artery and circumflex artery. On Color mode, the blood is blue in the left coronary artery (normally it is red) meaning that blood is going from coronary artery to $P A$.

\section{Discussion}

ALCAPA is certainly a rare malformation but it is not exceptional as it occurs in 1/30,000 living birth [1]. Like our 3 cases, it often happens as an isolate malformation except some few series that reported ALCAPA in association with coarctation of aorta [4]. The 3 cases were all aged less than 1 year old when the diagnosis was made; 2 of them were successfully operated but the third child is still waiting for surgical repair. In the absence of surgical repair, the mortality raises up to $90 \%$ by the age of 12 month-old [8]. Nevertheless $10-15 \%$ can survive until adulthood because of collateral branches that connect the coronary arteries [6], [7]. The symptoms of ALCAPA start typically by the $8^{\text {th }}$ week after birth when the PA pressure drops leading to hypoperfusion of myocardium because of 
the deoxygenated blood or stolen blood from LCA to PA. They start by myocardial ischemia, then by an infraction of the free wall of LV and culminate in LV failure and mitral regurgitation. Therefore the diagnosis of ALCAPA is made in a context of CHF; ECG is routinely used to seek for ischemia or infarction of LV. In the literature the common findings include antero-septal zone ST elevation and Q wave at D1 and AVL [2], [6], [12]. For this reason, a deep Q wave at D1, AVL, V5 and V6 in infants makes ALCAPA suspected. The commonest echographic sign is a LCA (more often than the RCA) that originates from the PA making the difference from ectopic LCA. The other signs include dilated RCA, mitral regurgitation, septal collateral branches realizing the image of "Christmas Tree", systolic dysfunction and dilated LV [13]. The multi-slice CT scan plays a key role in the diagnosis and preoperative assessment of this malformation as it provides noninvasive detailed pictures that can make catheterization and angiography needless. For this reason, some authors [10] state it is the first-line exam. The diagnosis of ALCAPA is an indication for surgical repair. Historically, surgeons used to perform ligation the origin of the LCA or its ostium on the PA. Then Takeuchi's technique was described and consisted of tunneling the LCA through the PA to ascending aorta [9]. The latest techniques recommend a linkage of the LCA to the ascending aorta either by re-implantation (procedure used for our 2 patients) or bypass. The others procedures depend on associated malformation. Prognosis was good for the patients who have been operated. According to Michielon et al. [5] the sooner a patient is operated the better the LV function. Thus in those patient treated late, LV function and myocardial perfusion can remain insufficient although repair is well performed. The LV function was completely recovered for the case 2 .

\section{Conclusion}

ALCAPA is a rare congenital disease to suspect in infant with CHF and lateral necrosis at ECG. The diagnosis of this malformation is possible in Sub-Saharan Africa. However, the treatment that is strictly surgical is to be performed in the developed countries.

\section{Abbreviations}

CHF: congestive heart failure;

CPB: cardiopulmonary bypass;

DCM: dilated cardiomyopathy;

ECG: electrocardiogram;

HLA: hypertrophy of the left atrium;

HRV: hypertrophy of the right atrium;

LA: left atrium;

LCA: left coronary artery;

LV: left ventricle;

LVEF: left ventricle ejection fraction;
PA: pulmonary artery;

$\mathrm{RA}$ : right atrium;

RCA: right coronary artery;

$\mathrm{RV}$ : right ventricle.

\section{References}

[1] Dodge-Khatami A, Mavroudis C, Backer CL. Anomalous origin of the left coronary artery from the pulmonary artery: collective review of surgical therapy. Ann Thorac Surg 2002; 74: 946-55.

[2] Keith JD. The anomalous origin of the left coronary artery from the pulmonary artery. Brit Heart J. 1959, 21:149-61.

[3] Kumar RV, Krishna LSR, Ramachandran G. Anomalous origin of the left coronary artery arising from the pulmonary artery: Reverse remodeling of coronary arteries following translocation operation. Indian $\mathrm{J}$ Thorac Cardiovasc Surg 2012; $28(2): 151-2$.

[4] Levin SE, Dansky R, Kinsley RH. Origin of left coronary artery from right pulmonary artery co-existing with coarctation of the aorta. Int J Cardiol 1990; 27:31-6.

[5] Michielon G, Di Carlo D, Brancaccio G. et al. Anomalous coronary artery origin from the pulmonary artery: correlation between surgical timing and left ventricular function recovering. Ann Thor Surg 2003; 76:581-8.

[6] Nakle N, Biscardi S, Lambert V, Sigal-Cinqualbre A, Epaud $\mathrm{R}$, Madhi F. Anomalie de naissance de la coronaire gauche à partir de l'artère pulmonaire révélée par une Bronchiolite. Rev Mal Resp 2012; 29: 912-15.

[7] Pena E, Nguyen TE, Merchant N, Dennie C. ALCAPA Syndrome: not just a pediatric disease. RadioGraphics 2009; 29:553-65.

[8] Shivalkar B, Borgers M, Daenen W, et al. ALCAPA syndrome: an example of chronic myocardial hypoperfusion? J Am Coll Cardiol 1994; 23:772-8.

[9] Toumpourleka M, Belitsis G, Alonso R, Rubens M, Moat N, Gatzoulis M. Late presentation and surgical repair of ALCAPA. Int J Cardiol 2015; 186:207-209.

[10] Toussaint M, Goube P, Kuoch V, Defrance C, Amrar-Venier F, Nicollet E, Gonin S, Busy F, Lardoux H. Origine anormale de la coronaire ga uche à partir de l'artère pulmonaire: place du scanner 64 coupes. J Radiol 2011; 92:1124-7.

[11] Trabelsi Sahnoun I, Abid L, Abid D, Triki F, Sahnoun M, Krichene S, Hentati M, Kammoun S. la naissance anormale du tronc coronaire gauche à partir de l'artere pulmonaire : etiologie de defaillance cardiaque chez le nourrisson. J. I. M. Sfax 2008; 15 (16):23 - 5 .

[12] Uysal F, Bostan OM, Semizel E, Signak IS, Asut E, Cil E. Congenital anomalies of coronary arteries in children:the evaluation of 22 patients. Pediatr Cardiol 2013;

[13] Wang S S, Chen X X, M D, Chen J M, Zhang Z W, MaY, Huang M P, Zhuang J. Echocardiographic findings of an anomalous origin of the left coronary artery in children and adolescents. Real or fake? J Ultrasound Med 2016; 35:59-66. 